
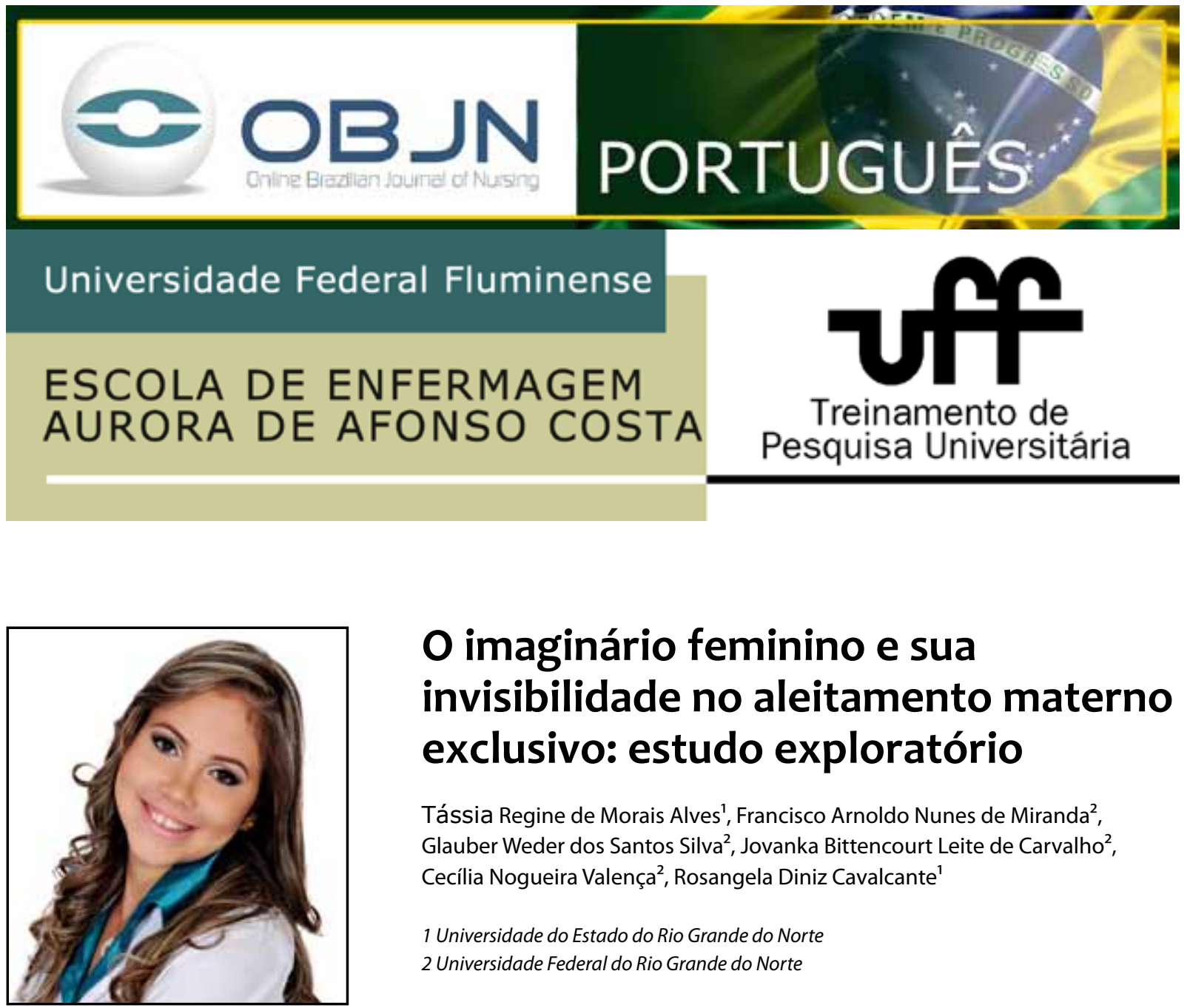

\title{
O imaginário feminino e sua invisibilidade no aleitamento materno exclusivo: estudo exploratório
}

\author{
Tássia Regine de Morais Alves ${ }^{1}$, Francisco Arnoldo Nunes de Miranda ${ }^{2}$, \\ Glauber Weder dos Santos Silva², Jovanka Bittencourt Leite de Carvalho², \\ Cecília Nogueira Valença ${ }^{2}$, Rosangela Diniz Cavalcante ${ }^{1}$ \\ 1 Universidade do Estado do Rio Grande do Norte \\ 2 Universidade Federal do Rio Grande do Norte
}

\section{RESUMO}

Objetivo: compreender a importância e as dificuldades que as mulheres encontram na adesão ao aleitamento materno exclusivo. Método: estudo de abordagem qualitativa, do tipo exploratório e descritivo. Foram realizadas entrevistas semiestruturadas com 14 mulheres. O tratamento dos dados se deu mediante a análise de conteúdo, na modalidade da análise temática. Resultados: a maioria das mulheres revelou conhecer a importância e os benefícios do aleitamento materno, por ser uma prática importante e por proporcionar uma boa condição de saúde e desenvolvimento ao filho. Aspectos que beneficiam a mulher que amamenta foram explicitados, porém, em menor intensidade quando comparável às relacionadas à saúde do bebê. Conclusão: Acentua-se a necessidade de incorporar práticas além da dimensão biológica, compreender as particularidades de cada mulher e incentivar o cuidar-se como importante para si.

Descritores: Aleitamento Materno; Saúde da Mulher; Saúde da Criança. 


\section{INTRODUÇÃO}

Assumindo as características da sociedade, pode-se afirmar que a maternidade é produto cultural, onde as relações de gênero se ancoram em desigualdades e na hierarquização do cuidar. Investe-se na mulher a perspectiva de essência universal da posição de cuidadora das crianças, destacando assim seu papel intrínseco de amamentadora como processo obrigatório em detrimento da invisibilidade do prazer e do cuidar-se como importante para si ${ }^{(1,2)}$.

Sabe-se que o aleitamento materno é recomendado mundialmente como a melhor forma de proporcionar nutrição adequada para o desenvolvimento e crescimento saudável do bebê até os seis meses de idade; além disso, está associado à redução da mortalidade infantil ${ }^{(3)}$.

Historicamente, tem sido identificado como a principal fonte de nutrientes para crianças, sendo um recurso e processo natural. Contudo, sabe-se que sua ocorrência/efetividade sofre fatores externos - de um lado, culturais, religiosos, demográficos e socioeconômicos; por outro, experiências anteriores negativas, primíparas, baixa escolaridade, mães jovens e solteiras ${ }^{(4)}$.

Em razão das vantagens que o aleitamento materno proporciona à díade mãe-filho, diversas estratégias foram instituídas com objetivo de incentivar a prática da amamentação para minimizar a mortalidade infantil no país. Entre as medidas estabelecidas, destaca-se o Programa Nacional de Incentivo ao Aleitamento Materno (PNIAM), que passou a fazer parte das Ações Integradas de Saúde, que relativa a intervenção ao obstáculo para não execução do aleitamento materno exclusivo, integrando campanhas e aperfeiçoamento dos profissionais.

Destarte, o Fundo das Nações Unidas para a Infância (UNICEF), o Ministério da Saúde (MS) e PNIAM estabelecem ações de proteção ao aleitamento materno exclusivo. Assim, a legislação brasileira protege a amamentação por meio de leis fundamentadas a partir das recomendações destes organismos, além de outros dispositivos legais que Ihe dão sustentação: Constituição Brasileira - 1988; Consolidação das Leis Trabalhistas; Portaria 2.051/2001 do Ministério da Saúde; Resoluções n 221 e 222 de 2002, da Agência Nacional de Vigilância Sanitária; e a Portaria 1.061/1992 do MS.

Entre tecnologias inseridas no processo de trabalho da atenção básica que podem propiciar a promoção do aleitamento materno exclusivo, a Visita Domiciliar (VD) é importante instrumento que permite o reconhecimento da realidade das puérperas e lactantes, pois estabelece vínculos com as usuárias ${ }^{(5)}$ e compreende aspectos imprescindíveis da dinâmica familiar no processo de amamentação.

Nesse sentido, mesmo diante dessas iniciativas no Brasil e, em especial, no município de Caicó, no Estado do Rio Grande do Norte, observa-se uma realidade negativa e índices insatisfatórios no que diz respeito à adesão ao aleitamento materno exclusivo nos primeiros meses de vida da criança ${ }^{(6)}$.

Frente o exposto e os reconhecidos benefícios que essa prática proporciona, questiona-se: as mulheres compreendem a importância do aleitamento materno exclusivo? Quais as dificuldades encontradas para adesão a prática do aleitamento materno exclusivo?

Quanto à relevância deste estudo e suas contribuições para a Enfermagem, faz-se razoável destacar que compete à/ao enfermeira/o ações e processo de cuidar no pré-natal e durante as consultas médicas e de enfermagem. Assim, admite-se a complexidade do ato de amamentar, além de aproximar da realidade, reconhecendo as dificuldades para a realização da amamentação exclusiva, tornando-se indicadores para uma prática 
educativa capaz de instilar confiança no procedimento e motivar para adoção e promoção deste hábito.

Concorda-se da existência, nesta área do conhecimento, de lacunas de estudos que investiguem as dificuldades que as mulheres encontram na adesão ao aleitamento materno exclusivo, além das recomendações para ampliar a produção científica que aborde esta temática ${ }^{(1)}$. Pretende-se, ainda, levantar subsídios para a reflexão e orientação das práticas dos profissionais de saúde, em especial o enfermeiro, no tocante ao planejamento de ações voltadas à problemática e cogitar sobre possíveis soluções para minimizar a prevalência do não aleitamento materno exclusivo.

O presente artigo, frente à sumarização introdutória de sua problemática, tem como objetivo compreender a importância e as dificuldades que as mulheres encontram na adesão ao aleitamento materno exclusivo.

\section{MÉTODOS}

Trata-se de um estudo exploratório e descritivo, com abordagem qualitativa. A abordagem qualitativa responde questões muito particulares, tais como o universo dos significados, dos motivos, das aspirações, das crenças, dos valores e das atitudes ${ }^{(7)}$.

A pesquisa foi realizada em quatro áreas de abrangência da Estratégia Saúde da Família (ESF) no município de Caicó, situado na microrregião do Seridó Ocidental do Estado do Rio Grande do Norte, por apresentar baixos índices de aleitamento materno exclusivo $(<50 \%)$ durante o período de janeiro a abril de 2012, segundo as informações no Sistema de Informação da Atenção Básica ${ }^{(6)}$.

Compôs a população do estudo 14 muIheres adstritas nas quatro áreas definidas para a pesquisa, por meio dos seguintes critérios elencados para a inclusão das participantes: residir nas áreas urbanas de cobertura da ESF, não estar amamentando ou não amamentar exclusivamente entre o primeiro e quarto mês pós-parto e ter realizado o pré-natal com os enfermeiros da ESF do município. Excluíram-se menores de 18 anos de idade.

A coleta de dados se deu no período de janeiro a março de 2013 por meio de uma entrevista semiestruturada, gravadas em aparelho eletrônico (mp4), realizadas durante visitas domiciliares após a leitura e assinatura do Termo de Consentimento Livre e Esclarecido. Iniciou-se a coleta das informações em atenção a Resolução n’ 466, de dezembro de 2012 do Conselho Nacional de Saúde (CNS). A pesquisa foi aprovada pelo Comitê de Ética em Pesquisa da Universidade do Estado do Rio Grande do Norte, e aprovada conforme CAAE no 03932312.1.0000.5294.

Analisaram-se os dados das entrevistas a partir da análise de conteúdo (AC), na modalidade de análise temática, com vista à identificação dos núcleos do sentido que permitiram trazer significados para o objeto esperado a partir das três fases complementares: a pré-análise, a exploração do material e o tratamento dos resultados, que incluem inferência e interpretações ${ }^{(7)}$.

Ressalta-se que este artigo constitui um recorte do projeto de iniciação científica intitulado Dificuldades encontras pelas mulheres no tocante a adesão ao aleitamento materno exclusivo, contemplado por bolsa de financiamento inserido no Programa Institucional de Bolsas de Iniciação Científica da Universidade do Estado do Rio Grande do Norte.

Atendendo a princípios éticos e para manter a privacidade das participantes da pesquisa, durante a apresentação dos resultados utilizou-se os códigos $\left(M_{1}\right.$ a $\left.M_{14}\right)$ para identificar os sujeitos. 


\section{RESULTADOS}

Entre as participantes do estudo, predominaram características como baixa escolaridade, renda familiar entre um e dois salários mínimos, profissão domésticas ou desempregadas, idade entre 25 e 29 anos e solteiras. Diante a análise de conteúdo, apresenta-se a seguinte categoria:

Imaginário feminino a respeito do aleitamento materno.

O aleitamento materno, além de suprir todas as necessidades nutricionais da criança nos primeiros meses de vida, proporciona, pelo contato físico entre mãe e filho, interações benéficas em ambos, que se constituirão no embasamento da concepção apropriada do mundo da criança $^{(8)}$.

As falas revelaram que o contato físico com o filho representa algo prazeroso para a mulher, uma vez que possibilita o fortalecimento de laços afetivos:

[...] tem a questão do vínculo com mãe, mãe e filho. (M13)

É um alimento natural, assim próprio para o bebê. Tem também a questão do afeto entre a mãe, né, e o filho. (M14)

O conhecimento relacionado à proteção contra doenças surge nos seguintes depoimentos:

É uma vacina natural, né? Livra o bebê de várias doenças e dá anticorpos, fora os benefícios para o organismo em si... (M2)

As propriedades do leite materno que são boas para o imunológico da criança [...] funciona como uma vacina, protege a criança de doenças como infecções e alergias. (M4)

Funciona como uma vacina, o enfermeiro me explicou. Imuniza muito o bebê. (M10)

Em relação à importância do aleitamento materno, há reconhecimento quanto ao valor nutricional:

[...] mas sei que é fonte de vitaminas, é bem rico para o bebê. (M9)

Eu sei que é bom por causa da nutrição né, que o leite materno nutre o bebê né, é um alimento completo, é rico... (M3)

O entendimento dos benefícios nutricionais para a criança é uma informação relevante considerada pelas mães. Porém, demonstram pouco conhecimento para si com incertezas acerca dos benefícios proporcionados pelo aleitamento materno exclusivo para a saúde da mãe:

[...] eu sei que é assim, bom para o crescimento né? A criança cresce sadia, mas não sei se existem benefícios para mim. Só para a criança, que eu saiba. (M5)

Não fui informada sobre benefícios para a mãe de dar o peito ao bebê. Mas o que importa é a saúde dele, né? (M7)

Sabe-se que a amamentação não beneficia somente a mãe ou a criança, mas a díade mãe-filho de forma única e positiva. A seguir, vantagens que a amamentação proporciona à saúde materna:

Os benefícios para mãe é a questão que ela perde o peso mais rápido; também 
tem a questão a renovação do sangue, melhora o imunológico da mulher também, evita câncer de mama, lembro desses. Mas eu sempre lia muito sobre amamentação. (M7)

Para mim, eu sei assim que evita o câncer de mama, câncer de útero. (M10)

Além dos fatores biológicos de proteção mencionados, outras vantagens que a amamentação proporciona incluem a praticidade e a isenção de despesas com substitutos do leite materno:

Para mãe é importante, né, também. Já li que evita hemorragia após o parto, câncer de mama. Sem falar na economia, não precisa comprar, nem colocar no fogo, está sempre pronto, essas coisas. (M8)

Eu dou leite de vaca para ele, ele gosta mais. Por isso, eu gasto muito. Eu sei que se ele só mamasse, eu economizaria bastante. (M14)

O conhecimento adquirido sobre os benefícios do aleitamento materno para a saúde da criança foi obtido por meio de ações educativas. As participantes conhecem a importância do aleitamento materno para o fortalecimento da cavidade oral do lactente conforme afirma abaixo:

Eu já fui para uma palestra que teve ali no colégio sobre amamentação e aprendi que é bom para os dentes. (M5).

Dificilmente o bebê adoece quando mama. É bom principalmente para os dentes, para ter os dentes saudáveis, é muito bom [...] (M6)

Pode também o aleitamento materno colaborar com melhor qualidade de vida da família, uma vez que a criança adoece menos:

É ótimo, pois ele realmente adoece menos, aí todo mundo aqui em casa fica tranquilo. A família toda relaxa. (M1)

É muito bom para criança, para mãe também, [...] e a criança adoece menos, e assim é bom para criança e para família por que ela fica saudável. (M9)

Aspectos importantes, como a satisfação e realização da mulher em amamentar o filho, foram mencionados:

A gente se sente realizada em poder amamentar o filho, é uma sensação que não dá, assim, nem para descrever. (M10)

Contribuindo com a elucidação do tema, são claros a idealização e o estímulo do aleitamento materno pelos meios de comunicação, conforme citado abaixo:

Eu vejo muito na TV o incentivo para dar só o peito para os nossos filhos. (M1)

Sei que é bom amamentar. Na televisão incentiva muito, né, as mães para amamentarem. (M11)

A banalização do sentimento da mãe, a falta de informação sobre as possíveis intercorrências por parte do profissional de saúde que a assiste e o estímulo midiático valorativo podem 
ser fatores para o abandono e desestímulo da amamentação:

A enfermeira dizia que era sempre para eu amamentar, mas nunca falou que poderiam aparecer esses problemas. Era como se, mesmo com todo esse sofrimento, eu ainda tivesse que dar o peito, mas eu não aguentava dar, era muita dor. Mas eu acho que ela era para dizer a realidade, porque na televisão, nessas coisas tudo é muito bonito, mas deveriam dizer assim que podiam surgir problemas durante a amamentação do filho, porque só falam as coisas boas. (M12)

Nas novelas sempre mostram as muIheres dando só o peito e muito feliz com isso. Por isso, o povo só sabe dizer que é para gente amamentar. Mas têm os problemas, os negócios que apareceram no peito e, mesmo assim, ficaram arrumando o jeito de curar para eu voltar a dar o peito, mesmo não tendo condições. (M6)

\section{DISCUSSÃO}

De uma forma consensual, atribuem-se, por evidências anátomofisiológicas, capacidades ao aleitamento materno que vão além de suprir todas as necessidades nutricionais do lactente nos primeiros meses de vida, na medida em que proporciona, pelo contato físico entre mãe e filho, interações benéficas em ambos, para uma subjetivação que constituirá o embasamento da concepção apropriada do mundo da criança ${ }^{(8)}$.

Nesse sentido, a lactação é algo complexo e envolve o conhecimento das mulheres sobre esta prática, que é permeada por concepções biomédicas e culturais, valores, crenças, experiências prévias e influências de familiares, sociedade e profissionais de saúde ${ }^{(9)}$.

A não adesão à prática do aleitamento materno pode estar relacionada à falta de conhecimento das mães referente à sua importância ou ligados a algum traço cultural, religioso, étnico e econômico onde ela se insere. Assim, reconhecendo a multidimensionalidade da questão, faz-se pertinente compreender que para que estas mulheres consigam estabelecer e manter a amamentação. Exige-se uma abordagem, que deve iniciar-se ainda no pré-natal, estendendo-se até o puerpério ${ }^{(10)}$.

No que se refere ao significado atribuído pelas mulheres sobre ao aleitamento materno, destaca-se a importância que o universo feminino comumente atribui como importante mecanismo de proteção de doenças.

Concorda-se que crianças menores de seis meses que não são amamentadas possuem risco elevado de não terem suas necessidades nutricionais atendidas e ocasionam aumento da mortalidade neonatal em $20 \%$. Além disso, possuem quatro vezes mais chances de mortalidade por doenças respiratórias, apresentando, por conseguinte, maiores índices de internações hospitalares. Isso posto, a morbidade e mortalidade infantil pode ser prevenida pela adesão ao aleitamento materno exclusivo(11).

O aleitamento confere proteção contra infecções respiratórias, sendo maior quando esta prática é exclusiva nos seis primeiros meses de vida, além disso, episódios de infecções respiratórias diminuem e, por conseguinte, menores chances de internações hospitalares ${ }^{(8)}$.

É percebível, nas falas analisadas no eixo categorial, que o valor nutricional e proteção imunológica são benefícios que merecem ênfase pelas participantes desse estudo, fazendo uma analogia entre o leite materno e as vacinas. Vale salientar que o leite materno possui todos 
os nutrientes que são essenciais para o desenvolvimento e o crescimento infantil, além de ser de fácil digestão quando comparado a leites de outras espécies, sendo capaz de atender às necessidades nutricionais da criança até os seis meses de vida e permanece um importante alimento fonte de nutrientes até os dois anos de idade, uma vez que é rico em vitaminas, proteínas e gorduras ${ }^{(8)}$.

Observa-se que a motivação para o aleitamento materno está centrada nos benefícios à saúde do filho - noutras palavras, o bebê é a razão da amamentação, levada a termo mesmo que proporcione um silenciamento, um não dizível dos benefícios da mãe, algo dicotômico: para o bebê, tudo; para a mãe, a invisibilidade. Isso demonstra a pouca valorização da amamentação à saúde materna: acredita-se que a mãe precisa se sentir estimulada para realizar essa prática de maneira satisfatória. Diante do exposto, as vantagens do aleitamento materno estão voltadas exclusivamente para a criança, deixando de lado a mãe. Protagonista desse processo, entende-se que a mulher também precisa se sentir valorizada e motivada para realizar tal prática.

Os momentos propriamente biológicos da maternidade, gravidez, parto e amamentação marcam profundamente a relação das mulheres com a saúde e, em última instância, com a medicina e a enfermagem. Isso porque esses momentos são em geral medicalizados, além disso pressupõem a responsabilidade das mulheres pela boa saúde do filho. Esta responsabilidade estende-se durante todo o período em que a criança depende da mãe e, muitas vezes, ela persiste até a idade a vida adulta ${ }^{(2)}$.

As mulheres são, em certa medida, agentes retransmissores do saber médico institucional que concerne seus próprios corpos, sem participar da produção deste saber. Ademais, elas estão sujeitas a uma hierarquia médica que se fundamenta em uma concepção de "natureza feminina": figura sensível, paciente, devota e sempre apta a cuidar dos outros. E uma destas representações diz respeito à saúde, já que as mulheres, por serem mães biológicas, acabam sendo as principais responsáveis pela saúde de seus filhos ${ }^{(2)}$.

Compreende-se o aleitamento materno como uma prática importante e adequada para a criança no tocante ao processo saúde-doença. Além disso, o conhecimento sobre amamentação foi adquirido por meio de palestras. O período pré-natal é uma época de preparação física e psicológica para o parto e para a maternidade, um momento de intenso aprendizado e uma oportunidade para os profissionais da equipe de saúde desenvolverem a educação como dimensão do processo de cuidar ${ }^{(12)}$.

Nessa perspectiva, a educação em saúde constitui um conjunto de saberes e práticas norteadas para a prevenção de doenças e promoção da saúde. Trata-se de um recurso por meio do qual o conhecimento cientificamente produzido no campo da saúde alcança a vida cotidiana das pessoas, uma vez que os condicionantes do processo saúde-doença oferecem subsídios para adoção de novos hábitos e comportamentos ${ }^{(13)}$.

Acredita-se que atividades educativas apresentem um impacto positivo na qualidade de vida das pessoas. Uma estratégia eficaz diz respeito ao grupo de gestantes, com o intuito de fortalecer a amamentação e promover a autonomia dessas mulheres. Esse momento precisa ser valorizado especialmente pelos profissionais de saúde, uma vez que constitui uma ferramenta de valor inestimável para a ampliação do conhecimento, em que as futuras mães poderão trocar experiências e esclarecer diversas dúvidas ${ }^{(14)}$.

Uma temática que poderá ser trabalhada durante as ações educativas, destaca-se a importância do aleitamento materno para desenvolvimento saudável da dentição. As falas revelam 
que as mulheres participantes reconhecem a amamentação como prática importante para o desenvolvimento e fortalecimento da dentição.

Indiscutivelmente, a amamentação constitui um exercício importante e adequado para a cavidade oral do lactente, tendo em vista que propicia uma melhor conformação do palato duro, que é essencial para o alinhamento correto dos dentes e uma boa oclusão dentária. A não adesão à prática da amamentação pode acarretar a ruptura no desenvolvimento motor-oral adequado, podendo prejudicar as funções de mastigação, deglutição, respiração e articulação dos sons da fala, dentre outras ${ }^{(8)}$.

A amamentação é a melhor forma de proporcionar o alimento para o crescimento e desenvolvimento adequado ao bebê, além de ser parte integral do processo reprodutivo, com impacto positivo à saúde materna ${ }^{(15)}$.

Atualmente, já se comprovam que a prática do aleitamento materno proporciona também vantagens para a saúde materna, pois, à medida que se inicia precocemente, ainda na primeira hora após o parto, há o estímulo à produção de ocitocina, que previne hemorragias no pós-parto, além de estimular a involução uterina, minimizando, assim, o risco de anemia, bem como fortalece o vínculo mãe-filho(16).

Durante décadas, os argumentos a favor do aleitamento materno ficaram centrados nos benefícios que essa prática proporciona à saúde da criança. Posteriormente, passou-se a dar ênfase para as vantagens que o aleitamento oferece à saúde materna ${ }^{(17)}$.

A prevenção contra o câncer de mama e a diminuição do sangramento pós-parto são aspectos que compõem as falas. Além disso, o fator da economia e praticidade do leite materno foi mencionado. A prática de aleitar ao seio associada à redução nos índices de câncer já está bem estabelecida. Estima-se que a probabilidade de contrair a doença diminua 4,3\% a cada 12 meses de amamentação. Essa proteção independe de idade, etnia, paridade e presença ou não de menopausa ${ }^{(8)}$.

A amamentação pode reduzir as chances do desenvolvimento do câncer de mama, pois essa condição induz o amadurecimento das glândulas mamárias, tornando as células mais "estáveis", menos suscetíveis ao aparecimento do câncer. Essa afirmação parte do pressuposto que a mulher, durante o aleitamento materno, se expõe menos aos hormônios estrógenos, pois com a dequitação da placenta há um aumento da prolactina e ocitocina, responsáveis pelo lactopoiese e seus níveis altos inibem o estrogênio. Sendo o câncer de mama uma patologia hormônio-dependente para o estrógeno, a amamentação torna-se um fator de proteção para essa doença ${ }^{(17)}$.

Sabe-se que os benefícios da amamentação para saúde da mulher são pouco abordados durante as consultas de pré-natal. Comumente, as informações são voltadas para a saúde da criança, embora reconheça-se que, para a mulher, a amamentação gera vantagens importantes. Destarte, é de suma importância que os profissionais de saúde valorizem a importância de sua atuação na promoção do aleitamento materno. Acredita-se que orientações durante todo o ciclo gravídico-puerperal são indispensáveis no sentido de informar adequadamente às mulheres quanto à relevância dessa temática para a proteção contra o câncer de mama.

Compreende-se que o universo feminino é permeado por vários fatores que nem sempre são considerados durante a atuação profissional, e os discursos técnicos e acadêmicos que sustentam tal prática estão direcionados às necessidades da criança, não contemplando as particularidades da mulher ${ }^{(18)}$.

$\mathrm{O}$ aleitamento materno pode melhorar a qualidade de vida das famílias, uma vez que as crianças amamentadas adoecem menos, 
necessitam de menos atendimento médico, hospitalizações e medicamentos e, por conseguinte, maior assiduidade ao trabalho dos pais, bem como a redução de gastos e situações estressantes melhorando na qualidade de vida das famílias ${ }^{(8)}$.

O vínculo entre a díade mãe-filho no processo prazeroso de amamentar apresenta um momento único que proporciona um íntimo contato, aumentando, assim, os laços de afeto e amor entre ambos. Assim, a valorização desse momento e a relação intrínseca que o ato de amamentar proporciona entre o binômio reúne momentos de interação, tornando a amamentação prazerosa e não obrigatória(19).

Nesse sentido, vale salientar a importância da assistência de pré-natal para a saúde materna e infantil. É imprescindível preparar e apoiar as futuras mães com apoio e estímulo ao aleitamento materno, bem como os benefícios que essa prática proporciona a mãe e filho. É o momento oportuno para realizar a promoção do aleitamento materno, pertencendo ao profissional incentivar à mulher a amamentar. Durante o acompanhamento de pré-natal, as orientações recebidas pelas gestantes aumentam seu conhecimento sobre o aleitamento materno e, por conseguinte, a prevalência desta prática social, especialmente se realizada por um profissional capacitado $^{(9)}$.

Atualmente, as estratégias de promoção do aleitamento materno estão ainda estruturadas em um modelo biologista e reducionista, incapazes de lidar com a subjetividade da muIher entre o desejo de querer e poder amamen$\operatorname{tar}^{(18)}$. Ao explorar pouco as potencialidades e fragilidades da amamentação, os profissionais concentram suas ações em intervenções mecanicistas, impetradas na obrigatoriedade de amamentar aquém da realidade da mulher. Sabe-se também que o incentivo na sociedade está bastante difundido pelos meios de comunicação, especialmente pela divulgação na mídia acerca dos benefícios gerados pelo aleitamento materno exclusivo.

A lactação insere-se em um contexto histórico, sociocultural e psicológico, de forma que esse processo representa significados diferentes para cada sociedade e para cada mulher. Neste contexto, as nutrizes são intensamente responsabilizadas e ao mesmo tempo excluídas da amamentação enquanto mulheres, e ora são sujeitos ativos, por terem a responsabilidade de amamentar, ora são passivos, pois seus sentimentos e desejos não são ponderados neste processo(18).

A divulgação dos benefícios da amamentação tem constituído uma estratégia universal no meio científico e amplamente difundida nos meios de comunicação em massa. Desta forma, outro aspecto presente nas falas foi a idealização feita pela mídia, enaltecendo essa prática que parece ser isenta de dificuldades.

No presente estudo, a mulher demonstrou frustração diante da vivência de uma realidade imperfeita, repleta de dificuldades e, distante, sobretudo, da idealização que a mídia repassa em que a amamentação se constitui uma prática geradora de felicidade e prazer. É perceptível a falta de sensibilidade de alguns profissionais de saúde frente à dor da mulher. Esta postura verticalizada e reducionista não possibilitou o apoio necessário à mulher e configurou como um dos fatores de desestímulo à amamentação.

A maioria das mulheres idealiza a amamentação como um processo natural e que, entretanto, não encontrará dificuldades. Contudo, para desenvolver habilidades para amamentar com o sucesso esperado, é necessário receber várias informações. Os esforços dos profissionais de saúde necessitam ser direcionados para facilitar esse processo de aprendizado e adaptação da mulher nesse novo papel materno, pois a insensibilidade dos profissionais de saúde, ou mesmo da família, frente à dor da mulher pode 
ser um fator que desperta nela sentimentos de solidão e isolamento, fazendo-a abandonar o aleitamento materno ${ }^{(20)}$.

\section{CONCLUSÃO}

As participantes do estudo revelam reconhecer a importância do aleitamento materno exclusivo ao ressaltarem as boas condições para o desenvolvimento da criança tanto pelo valor nutritivo e imunológico quanto pelo estreitamento das relações afetivas entre mãe e filho. Os aspectos relacionados aos benefícios para a mulher que amamenta foram menos revelados quando comparados aos relacionados ao bebe, tornando o binômio mãe-filho algo dicotômico: de um lado o bebê/criança com centralidade das ações de promoção e prevenção e produtora de sentido para ambos, do outro a invisibilidade da mãe como partícipe das vantagens desse ato da vida humana.

Influências da mídia e por parte de enfermeiros/as durante consulta pré-natal foram mencionadas como fatores valorativos, porém pouco esclarecedores dos efeitos para a mãe. Entretanto, relata-se a dificuldade de amamentar exclusivamente frente às intercorrências da amamentação e que orientações quanto a esta possibilidade não são mencionadas e esclarecidas em consultas, revelando fragilidades na superação de obstáculos, sendo a lactante culpabilizada pelo não seguimento da amamentação.

Reconhece-se a lacuna do estudo quanto ao número de sujeitos estudados, sendo os resultados estreitamente relacionados às condições sociopsicossociais dos mesmos, podendo encontrar outras realidades em distintas dimensões. Porém, não o torna menos relevante, pois traz a invisibilidade da mãe na díade proposta pelas recomendações ministeriais sobre aleitamento materno exclusivo, entendendo que as significações atribuídas a este processo interferem na sua eficácia.
Estudos nessa perspectiva devem ser encorajados, pois, apreendem-se as dimensões que podem dificultar a amamentação, delineando um novo caminho para a enfermagem atuar de modo mais empático e direcionado à especificidade de cada mulher.

\section{REFERÊNCIAS}

1. Cadoná E, Strey MN. A produção da maternidade nos discursos de incentivo à amamentação. Rev. Estud. Fem. 2014; 22(2):477-499.

2. Miskolci R. Dar a vida e cuidar da vida: feminismo e ciências sociais. Cad. Saúde Pública (Rio de Janeiro). 2006 ago; 22(8):1761-1765.

3. Caminha MFC, Serva VB, Arruda IKG, Filho MB. Aspectos históricos, científicos, socioeconômicos e institucionais do aleitamento materno. Rev Bras Saúde Matern Infant. 2010;10(1):25-37.

4. Cavalcanti SH, Caminha MFC, Figueiroa JN, Serva MV, Cruz RS, Lira PL, et al. Factors associated with breastfeeding practice for at least six months in the state of Pernambuco, Brazil. Rev Bras Epidemiol [internet]. 2015 [Cited 2015 mar 20];18(1):208-219. Available from: http://dx.doi. org/10.1590/1980-5497201500010016

5. Lionello CDL, Duro CLM, Silva AM, Witt RR. The performance of family health nurses in home care. Rev. Gaúcha Enferm. [Internet]. 2012 [cited 2015 may 30];33(4): 103-110. Available from: http:// dx.doi.org/10.1590/S1983-14472012000400013

6. Brasil. Ministério da Saúde. Sistema de Informação da Atenção Básica. Brasília, DF; 2012.

7. Minayo MCS (Org). Pesquisa social: teoria, método e criatividade. 29.ed. Rio de Janeiro: Vozes; 2010.

8. Brasil. Ministério da Saúde. Secretaria de Atenção à Saúde. Departamento de atenção Básica. Saúde da Criança: Nutrição Infantil Aleitamento Materno e Alimentação complementar. Brasília, DF; 2009.

9. Fonseca-Machado MO, Paula MSR, Parreira BDM, Stefanello J, Gomes-Sponholz F. Comparação do conhecimento sobre aleitamento materno entre mulheres no período pós-parto. Rev enferm UERJ. 2013;21(1):66-72. 
10. Fonseca MO, Pereira BDM, Douglas MC, Machado AM. Aleitamento materno: conhecimento de mães admitidas no alojamento conjunto de um hospital universitário. Cienc Cuid Saúde. 2011;10(1):141-149.

11. Silva AC, Davim BMR. Mulher trabalhadora e fatores que interferem na amamentação: revisão integrativa. Rev Rene. 2012;(13)5:1208-17.

12. Roig AO, Martínez MR, García JC, Hoyos SP, Navidad GL, Álvarez JCF, et al. Factors associated to breastfeeding cessation before 6 months. Rev. Latino-Am. Enfermagem [Internet]. 2010 [cited 2015 may 30];18(3): 373-380. Available from: http://dx.doi.org/10.1590/S010411692010000300012

13. Santana MCCP, Goulart BNG, Chiari BM, Melo AM, Silva EHAA. Aleitamento Materno em Prematuros: atuação fonoaudiológica baseada nos pressupostos da educação para promoção da saúde. Ciênc saúde coletiva. 2010;15(2):411-417.

14. Fonseca-Machado MO, Haas VJ, Stefanello J, Nakano ANS, Gomes-Sphanolz F. Breastfeeding: knowledge and practice. Rev Esc Enferm USP [internet]. 2012 [Cited 2015 feb 20];46(4):809-815. Available from: http://www.scielo.br/pdf/reeusp/ v46n4/en_04.pdf

15. Kalinowski LC, Favero L, Carraro TE, Wall ML, Lacerda MR. Postpartum primipara at home and associated nursing care: a data-based theory. Online braz j nur [Internet] 2012 [cited 20 apr 2015];11(3):701-719. Available from: http://www. objnursing.uff.br/index.php/nursing/article/ view/3852

16. Carvalho ACO, Saraiva ARB, Gonçalves GAA, Soares JR, Pinto SL. Aleitamento materno: promovendo o cuidar no alojamento conjunto. Rev Rene. 2013;14(2):241-251.

17. Gradim CVC, Magalhães MC, Faria MCF, Arantes CIS. Aleitamento materno como fator de proteção para o câncer de mama. Rev Rene. 2011;12(2):358-364.
18. Marques DM, Pereira A. Amamentar: sempre benefícios, nem sempre prazer. Ciênc cuid saúde. 2010;9(2):214-219.

19. Teixeira MM, Vasconcelos VM, Silva DMA, Martins EMCS, Martins MC, Frota MA. Primiparae perception on guidance in prenatal care regarding breastfeeding. Rev Rene [internet]. 2013 [Cited 2015 feb 20];4(1):179-186. Available from: http:// www.revistarene.ufc.br/revista/index.php/revista/article/view/209/pdf_1

20. Santana MCCP, Goulart BNG, Chiari BM, Melo AM, Silva EHAA. Aleitamento Materno em Prematuros: atuação fonoaudiológica baseada nos pressupostos da educação para promoção da saúde. Ciênc. saúde coletiva. 2010;15(2):411-417.

Todos os autores participaram das fases dessa publicação em uma ou mais etapas a seguir, de acordo com as recomendações do International Committe of Medical Journal Editors (ICMJE, 2013): (a) participação substancial na concepção ou confecção do manuscrito ou da coleta, análise ou interpretação dos dados; (b) elaboração do trabalho ou realização de revisão crítica do conteúdo intelectual; (c) aprovação da versão submetida. Todos os autores declaram para os devidos fins que são de suas responsabilidades o conteúdo relacionado a todos os aspectos do manuscrito submetido ao OBJN. Garantem que as questões relacionadas com a exatidão ou integridade de qualquer parte do artigo foram devidamente investigadas e resolvidas. Eximindo, portanto o OBJN de qualquer participação solidária em eventuais imbróglios sobre a materia em apreço. Todos os autores declaram que não possuem conflito de interesses, seja de ordem financeira ou de relacionamento, que influencie a redação e/ou interpretação dos achados. Essa declaração foi assinada digitalmente por todos os autores conforme recomendação do ICMJE, cujo modelo está disponível em http://www. objnursing.uff.br/normas/DUDE_final_13-06-2013.pdf

Recebido: 01/06/2015

Revisado: 05/04/2016

Aprovado: 05/04/2016 